Tamil Nadu, India

kamala.thiagarajan@gmail.com Cite this as: BMJ 2021;374:n2005 http://dx.doi.org/10.1136/bmj.n2005 Published: 19 August 2021

\title{
Covid-19: How Kerala kept itself above water in India’s devastating second wave
}

\section{India is one of the worst hit countries in the pandemic, but one state has fared comparatively well. Kamala Thiagarajan asks what Kerala did differently}

\section{Kamala Thiagarajan freelance journalist}

India's first confirmed case of covid-19 was detected in the southern state of Kerala on 27 January 2020. Despite being one of the worst affected states-with over three million recorded cases, a quarter of infections in India-Kerala has the lowest covid death rate in the country at $0.4 \%$, less than a third of the national average of $1.3 \%$. As of 8 August, Kerala had 17654 recorded deaths.

Kerala, population 34 million people, is not the richest state in the country (it ranks 11th for size of economy); nor is it the biggest or smallest in terms of size or population. What it did have is a public health plan and long term investment in healthcare.

Systematic investment in public health by successive Keralan governments may have paid off. According to National Health Accounts reports, ${ }^{1}$ in 2016 the state topped the country in annual per capita healthcare spending with Rs7169 (£70; €82; \$97)-double the all India average of Rs380o.

In the most recent state budget in June 2021, Kerala officials invested a further Rs200 ooo for pandemic related medical emergencies and in helping those in need because of prolonged lockdowns. The budget also earmarked Rs636m to set up 10-bed isolation wards for contagious diseases in every community health centre and public hospital. ${ }^{2}$

Rajeev Sadanandan, chief executive of Health Systems Transformation Platform, who advised the government on its covid response, says "Kerala's lower case fatality rate was due to the availability of healthcare resources, distributed equitably across the state; free and aggressive management; and the health awareness of the people, which prompted them to seek medical help at the slightest symptom."

Rijo M John, a health economist and adjunct professor at the Rajagiri College of Social Sciences in Kochi, Kerala, told The BMJ that even during the peak of India's second wave, when there were over 40000 cases a day in the state, "hospital infrastructure wasn't overwhelmed, though it did reach its maximum capacity."

The second wave has created an unprecedented demand for medical oxygen. Nearly 9000 tonnes were used across India between mid-April and 13 May compared with 3095 tonnes during the first wave in August 2020. "The production, supply, and management of medical oxygen in Kerala was better than in other states," says Jijo P Ulahannan, associate professor of physics at the Government College of Kasaragod, Kannur University. Vigilant monitoring by state authorities and volunteers at a district level ensured adequate supply, he says. "New plants were installed in some medical colleges and major hospitals. The oxygen requirement remained under control."

Even at the peak of India's second wave, Kerala had enough oxygen. It produced twice as much as it required and supplied to other states such as Karnataka, Tamil Nadu, and Goa. ${ }^{3}$

\section{Test and trace}

What also helped was experience in handling public health emergencies. Kerala built a surveillance system for infectious diseases after a deadly outbreak of Nipah virus in 2018. It also established networks of volunteers to help with rescue and rehabilitation after two devastating floods in 2018 and 2019.

These disasters made local health and government authorities more vigilant. "All the active social networks that helped distribute food and relief materials to the needy during the floods were deployed for covid as well, especially during the lockdowns," says T S Anish, associate professor in community medicine at the Government Medical College in Thiruvananthapuram, "The state's strength lies more in its grassroots level public health systems, rather than in its big hospitals."

Kerala started tracking covid infections as early as January 2020, enabling it to "anticipate surges and take adaptive steps," says Sadanandan. "Kerala strategy since May 2020 was to ensure that the surge in cases never exceeded the capacity in hospitals, so that health systems were never overwhelmed," he says, "Unlike other states, Kerala never had clearly distinguishable periods of waves and calm."

Rigorous and consistent tracking, testing, and contact tracing from early on were key to controlling infections, says John.

Results from the fourth national serosurvey show that Kerala was able to identify and report one in six cases, while the rest of India was able to identify one in every $33^{4}$ (for comparison, Bihar state identified 1 in 134, Uttar Pradesh 1 in every 100, and Madhya Pradesh 1 in 86).

The state focuses on testing everyone who comes into contact with someone with covid-19, even if they have no symptoms, Anish says. This targeted tracing made best use of the state's limited testing infrastructure -47 of India's 1291 government laboratories, and 121 of its 1473 private laboratories are located in Kerala. ${ }^{5}$ Most of the surges in infections followed events and social gatherings, such as Onam 
(the state's harvest festival celebrations in August) and the state elections held in April.

Says Anish, "Kerala has detected three million of India's 30 million reported covid cases to date, which is around $9 \%$ of the state's population. In other states, that figure hovers around $2.5 \%$, so in Kerala, detection is three times the national average."

This did come with political risk: "When you have more targeted testing per million population, you tend to pick up more cases. The downside is that the state's positivity rate goes up, giving the impression that infections are raging out of control," John says. But the decision paid off, he says: more targeted testing allowed the state to catch infections before major outbreaks began.

\section{Delta strike}

Still, no one anticipated the emergence of the delta variant, which became dominant in India by the second week of April. As clusters grew, Kerala's contact tracing was rendered ineffective. The state was, however, fortunate in being hit slightly later than other parts of India, which allowed time to prepare, says Sadanandan.

Kerala's relative success in managing the pandemic means that there are many more susceptible people exposed to the highly infective delta variant, says K Srinath Reddy, president of the Public Health Foundation of India. "Kerala is experiencing a drawn out delta strike," he says.

One of its biggest vulnerabilities remains: the proportion of people aged over 60 is $15 \%$-double that of the rest of India. A rapid vaccination effort targeted at older people has so far helped prevent many deaths. As of 9 August, around $43 \%$ of Kerala's population had been vaccinated with at least one dose ${ }^{6}$ compared with $29 \%$ in neighbouring Maharashtra and $27 \%$ in Tamil Nadu. ${ }^{7}$ Kerala also reports zero wastage of doses. "Better trained healthcare workers, less vaccine hesitancy, and better management of vaccination sessions have all played a role," says John.

Reddy says the state must improve homecare support and monitoring, early hospital transfers of patients with serious symptoms, and containment measures in high intensity districts, even as vaccination is sped up.

Kerala's healthcare response looks good compared with that of other Indian states, says Anish, but not compared with other countries, especially in terms of vaccination. "Our current vaccination coverage isn't enough to prevent a third wave,” he says.

\section{Trust and community}

Protecting the various ethnic communities of Kerala was a substantial public health challenge. There are 35 in the state, accounting for $5 \%$ of the total population. Radio shows and videos in various languages helped spread awareness during the early days of the epidemic in 2020. Accredited social health activists (ASHAs) were deployed to these communities with the video and audio content. There was regular monitoring by health officials and tight entry and exit restrictions. Although covid inevitably found its way to some hamlets during the second wave, doctors and health inspectors trekked through jungle terrain, crossing rivers on foot, to offer testing and emergency care. One far flung area, Edamalakkudy, $40 \mathrm{~km}$ from Munnar in the Western Ghats mountains, managed to remain covid-19 free for most of the pandemic and has only recently seen its first two cases. ${ }^{8}$

Such efforts have earned officials a high degree of trust from citizens. This may have been further enhanced by the state's relatively transparent and accessible reporting. A study published in BMC Public Health in June rated it as one of the better in the country at data reporting, and under-reporting of covid-19 deaths was lower than in the rest of India. 9 However, a separate study by some of the same authors, published as a preprint, pointed out that Kerala had also stopped listing comorbidities for covid deaths, which could lend credence to accusations that it was misclassifying some as not due to covid-19. ${ }^{10}$

Competing interests: I have read and understood BMJ policy on declaration of interests and have no relevant interests to declare.

Provenance and peer review: Commissioned; not externally peer reviewed.

National health accounts estimates for India. 2018. https://main.mohfw.gov.in/sites/default/files/NHA_Estimates_Report_2015-16_0.pdf

2 Health takes prime spot in Kerala budget. The Hindu 2021 Jun 4. https://www.thehindu.com/news/national/kerala/health-takes-prime-spot-in-kerala-budget/article34725978.ece

3 Jacob J. How Kerala ramped up oxygen capacity and supply. India Today 2021 Apr 27. https://www.indiatoday.in/india-today-insight/story/how-kerala-ramped-up-oxygen-capacityand-supply-1795614-2021-04-27

4 Bihar detected only 1 in 134 Covid cases, UP 1 in 100, Kerala 1 in six, govt data shows. The Print 2021 Jul 30. https://theprint.in/health/bihar-detected-only-1-in-134-covid-cases-up-1-in-100kerala-1-in-six-govt-data-shows/705950/

5 Number of government and private testing centers for covid-19 across India as of August 92021. Statista https://www.statista.com/statistics/1104075/india-coronavirus-covid-19-public-privatetesting-centers-by-state/

6 Keral: Covid-19 battle. GoK dashboard. 9 Aug 2021. https://dashboard.kerala.gov.in/covid/ Covid-19 India. https://www.covid19india.org/

8 Vellaam S. After 16 months of staying safe, two COVID-19 cases reported in Kerala tribal hamlet. New Minute2021 Jul 14.https://www.thenewsminute.com/article/after-16-months-staying-safetwo-covid-19-cases-reported-kerala-tribal-hamlet-152299

9 Vasudevan V, Gnanasekaran A, Sankar V, Vasudevan SA, Zou J. Disparity in the quality of COVID-19 data reporting across India. BMC Public Health 2021;21:1211. doi: 10.1186/s12889-021-11054-7 pmid: 34167499

10 Vasudevan V, etal. 100+ covid-19 websites and apps: yet a lack of granular data from India. OSF Preprints 2021. doi: 10.31219/osf.io/wa3gn 